\title{
Psychiatric Disorders and Recidivism among Korean Adolescents on Probation or Parole
}

\author{
Yooli Lim¹, Eun-Jin Park², and Bongseog Kim ${ }^{1 凶}$ \\ ${ }^{1}$ Department of Psychiatry, Sanggye Paik Hospital, Inje University, Seoul, Republic of Korea \\ ${ }^{2}$ Department of Psychiatry, Ilsan-Paik Hospital, Inje University, Goyang, Republic of Korea
}

Objective The percentage of repeat offenders is increasing among juvenile offenders in Korea. The assessment and treatment of the mental health of young offenders may play an important role in reducing the recidivism rate of adolescents. This study examined the prevalence of psychiatric disorders among adolescents on probation or parole and the risk of recidivism associated with specific psychiatric disorders.

Methods We studied 120 adolescents on probation. The Mini-International Neuropsychiatric Interview and Conners' Rating Scale-Revised were used to diagnose psychiatric disorders.

Results Almost half of the juvenile offenders had psychiatric disorders, including alcohol use disorder (19.17\%), bipolar disorder (18.33\%), antisocial personality disorder (11.67\%), and attention-deficit/hyperactivity disorder (10.83\%). Alcohol use disorder was significantly associated with repeated offenses, but psychiatric disorders, excluding alcohol use disorder, were not significantly associated with repeated offenses.

Conclusion These results suggested that the development of education and treatment programs for psychiatric disorders, including alcohol use disorder, among juvenile offenders on probation or parole may help to prevent repeated criminal behaviour.

Psychiatry Investig 2018;15(6):561-567

Key Words Criminology, Young offenders, Juvenile offenders, Prevalence, Recidivism.

\section{INTRODUCTION}

The number of juvenile offenders in Korea has increased by $29.4 \%$ since 2002 , and they account for $5.1 \%$ of all criminal offences. ${ }^{1,2}$ The number/percentage of young offenders in Korea is increasing because of the increasing population, which causes serious social problems. Therefore, interest in mental health services for young offenders is increasing.

In western nations, the increasing numbers of young offenders have stimulated studies on the prevalence of mental illnesses among young offenders. Among these studies, the percentages of these disorders vary: substance use disorder (13-50\%), major depressive disorder (6.3-29.2\%), psychosis

Received: March 4, 2017 Revised: June 21, 2017

Accepted: November 30, 2017

$\triangle$ Correspondence: Bongseog Kim, MD, PhD

Department of Psychiatry, Sanggye Paik Hospital, Inje University, 1342 Dongil-ro, Seoul 01757, Republic of Korea

Tel: +82-2-950-1082, Fax: +82-2-950-8069, E-mail: kimbs328@paik.ac.kr

(c) This is an Open Access article distributed under the terms of the Creative Commons Attribution Non-Commercial License (http://creativecommons.org/licenses/bync/4.0) which permits unrestricted non-commercial use, distribution, and reproduction in any medium, provided the original work is properly cited.
(2.7-11.3\%), conduct disorder (31-52.8\%), attention deficit/ hyperactivity disorder (ADHD; 11.3-45\%), and personality disorder (36\%). ${ }^{3-7}$ An American study of 10-18-year-old children and adolescents in juvenile reformatories $(n=1,829)$ reported that $63.3 \%$ of the males and $71.2 \%$ of the females had a mental illness, and this percentage was 3-4-fold higher than the percentage of mental illnesses in the general adolescent population. ${ }^{3}$ Furthermore, over half of these subjects met the diagnostic criteria for substance use disorder. ${ }^{3}$ Wasserman et al. ${ }^{8}$ reported that $45 \%$ of the boys and $50 \%$ of the girls have at least one psychiatric disorder at probation intake. Because of the differences in the participants (numbers, ages, and genders), juvenile justice systems, and diagnostic tools, the prevalences of psychiatric disorders in juvenile offenders vary among the studies. However, most confirmed that psychiatric disorders, including substance use disorder, major depressive disorder, psychosis, conduct disorder, ADHD, and personality disorder, are common among juvenile offenders in western countries.

In Korea, few domestic studies have been conducted on mental illness in juvenile criminals. Park ${ }^{9}$ reported that juvenile 
inmates in 50 Korean prisons who had committed violent crimes had more psychiatric conditions, including depression, paranoia, hypomania, schizophrenia, and antisocial traits, compared to the general Korean youth population. However, most mental illness research in Korea has focused on children and adolescents outside of the criminal justice system.

Among juveniles, the percentage of first-time offenders has been gradually decreasing, whereas the percentage of repeat offenders has been increasing. ${ }^{1}$ Cottle et al. ${ }^{10}$ reported that many factors, including family and social factors, offense history, educational factors, IQ, mental health status, and, especially, substance abuse, conduct problems, anxiety, and stress, predict juvenile recidivism. A study of violent adolescent criminals and the incidence of psychiatric disorders reported a recidivism rate of $64.6 \%$ among adolescents with mental disorders, with $14.3 \%$ having at least 6 previous convictions. Thus, psychiatric disorders and recidivism in young offenders are highly related. ${ }^{9}$ A study of the contribution of psychiatric disorders to juvenile recidivism reported that externalizing disorders are associated with an increased risk of recidivism for both genders and that comorbid substance use disorders and affective disorders are associated with an increased risk for girls. ${ }^{11}$ Substance use disorder and co-occurring psychiatric disorders predict juvenile recidivism. ${ }^{12,13}$ Thus, the assessment and treatment of the mental health of young offenders may help to reduce the second offense rate of adolescents.

In order to improve the mental health and recidivism rate of young offenders, a comprehensive investigation of mental illnesses among domestic young offenders is needed. In the present study, we investigated the prevalence of psychiatric disorders among adolescents on probation or parole and the risk of recidivism according to specific psychiatric disorders with both structured interviews and self-report surveys at a probation centre in Korea. We hypothesized that individuals with psychiatric disorders have a greater recidivism risk.

\section{METHODS}

\section{Participants}

This preliminary study investigated mental illnesses in adolescent inmates in South Korea. Probation is a system to prevent recidivism and to help returning to society by correcting and rehabilitating juvenile offenders without accepting them at the correctional institution. Juvenile offenders should attend the lecture at the probation center during probation. Of the probation cases, including intensive, major, and general supervision probation, adolescents less than 19 years old who visited the probation office in Seoul because of orders to attend a lecture between August 6, 2014 and November 19, 2014 were selected as subjects. The purposes and procedures of the study were explained to the participants, and 120 participants volunteered. Written informed consents were obtained, and self-report tests and interviews by psychiatrists and clinical psychologists with appropriate educational credentials were administered after mandatory treatment.

This study was reviewed and approved by the Institutional Review Board of Sanggye Paik Hospital (SPIRB-2015-01-012) and was performed in accordance with the ethical standards of the 1964 Declaration of Helsinki and its later amendments.

\section{Measures}

We conducted self-report tests and structured diagnostic interviews to assess the demographic characteristics and prevalences of psychiatric disorders among the participants.

\section{Demographic characteristics}

Age, gender, socioeconomic status, and number/type(s) of crimes committed were recorded for each participant. The participants' living situations were recorded as living with both parents, a single parent, or non-parent(s). Annual family income was recorded as less than 10 million, 10-20 million, 20-30 million, or greater than 30 million won. Recidivism was defined as prior involvement with the criminal justice system. Those sentenced to their first probation were classified as the first offense group, while those on probation two or more times were classified as the repeat offense group. The reason for probation was recorded as a property crime (e.g., theft, fraud, or blackmail), violent crime (e.g., murder, robbery, assault, or arson), sex crime (e.g., rape or sexual assault), drug-related crime, domestic violence, traffic violation, obstruction of law enforcement, impaired driving, or other crimes.

\section{Neuropsychiatric evaluation and diagnosis}

\section{Mini-International Neuropsychiatric Interview}

The revised Mini-International Neuropsychiatric Interview (MINI) ${ }^{14}$ was used to diagnose psychiatric disorders in the participants. The MINI consists of a structured interview of the characteristics of Axis I disorders according to the Diagnostic and Statistical Manual of Mental Disorders, 4th revision (DSM-IV) and the International Statistical Classification of Diseases, 10th revision. The reliability and validity of the Korean version of the MINI has been demonstrated, and its administration time is $18.7 \pm 11.6 \mathrm{~min} .{ }^{15}$ The MINI can be used to diagnose major depressive disorder, dysthymia, bipolar disorder, panic disorder, agoraphobia, social phobia, obsessive-compulsive disorder, posttraumatic stress disorder, alcohol dependence, alcohol abuse, schizophrenia, delusional disorder, generalised anxiety disorder, somatoform disorder, adjustment disorder, and antisocial personality disorder and 
evaluate suicidal ideation. The Korean MINI uses structured questions that make the interview simple, fast, and objective. The MINI can also evaluate past psychiatric problems (e.g., mania, hypomania, or psychotic symptoms), which are considered when diagnosing psychiatric disorders. For most MINI modules, negative answers to 2-4 questions are used to rule out a psychiatric disorder. Positive answers are explored with additional questions addressing other diagnostic criteria.

\section{Conners-Wells' Adolescent Self-Report Scale: Short Form}

We used the Conners-Wells' Adolescent Self-Report Scale: Short Form to diagnose ADHD. This test is a self-report test for adolescents that is part of the Conners' Rating Scale-Revised used by parents, teachers, and youth for diagnosing ADHD. The scale consists of 27 questions with the answers ranked on a Likert scale from 0 (not true at all) to 3 (very frequently). The questions assess cognitive factors, hyperactivity, conduct problems, and an ADHD index. The minimum score for an ADHD diagnosis is 41 points at $13-14$ years of age, 44 points at 15 , and 42 points at $16-18$. In this study, we used a 42-point criterion because the mean age of the participants was 16.34 years. The internal consistency (Cronbach's $\alpha$ ) of the Conners-Wells' Adolescent Self-Report Scale: Short Form is $0.88 .^{16}$

\section{Statistical analyses}

Descriptive analyses were used to estimate the prevalences of psychiatric disorders and percentages of participants according to demographic characteristics and probation reasons. Chi-square tests were used to assess the differences between first-time and repeated offenders. We predicted that recidivism would differ according to the presence of psychiatric disorders via logistic regression. The covariates included age, gender, living with parents, annual family income, probation reason, and suicidality as in previous studies. ${ }^{10}$ The data were analysed with Statistical Analysis System software, version 9.0 (SAS 9.0; SAS Institute Inc., Cary, NC, USA). P values less than 0.05 were considered statistically significant.

\section{RESULTS}

\section{Demographic characteristics}

The mean age of the participants was 16.34 years (standard deviation, 1.54). Ninety-seven participants $(80.8 \%)$ were men, and 23 (19.2\%) were women. Fifty-three participants (44.2\%) lived with both parents, 56 (46.7\%) lived with one parent, and 11 (9.2\%) lived with grandparents, siblings, or a spouse. Only 68 participants responded to the question regarding annual family income; of these, 12 (10.0\%) reported an annual family income of less than 10 million won, 25 (20.8\%) reported
10-20 million won, 15 (12.5\%) reported 20-30 million won, and $16(13.3 \%)$ reported more than 30 million won. Fiftyseven participants $(47.5 \%)$ were first-time offenders, and 63 (52.5\%) were repeat offenders. For offense number, 57 (47.5\%), 36 (30.0\%), 17 (14.2\%), and 10 (8.3\%) committed a first, second, third, and over four crimes, respectively.

\section{Probation reasons}

Multiple responses were permitted, and only 1 participant did not answer. Fifty-eight participants (48.7\%) committed property crimes (e.g., theft, fraud, or blackmail), 33 (27.7\%) committed violent crimes (e.g., murder, robbery, assault, or arson), 4 (3.4\%) committed sex crimes (e.g., rape or sexual assault), and 15 (12.6\%) committed traffic violations. Two (1.7\%) were arrested for impaired driving, 2 (1.7\%) obstructed law enforcement, $1(0.8 \%)$ was arrested for narcotics possession, 1 (0.8\%) committed domestic violence, and 14 (11.7\%) committed other crimes, such as manipulation of official documents, defamation of character, or breaking and entering.

\section{Psychiatric diagnoses}

Table 1 lists the psychiatric disorders, including dual diagnoses, in the 53 of the 120 participants (44.2\%). Twenty-six participants had over 2 psychiatric disorders.

\section{Demographic characteristics in first-time and repeat offenders}

Table 2 reports the demographic characteristics of firsttime and repeat offenders. Repeat offenders were significant-

Table 1. Psychiatric disorders among the participants $(N=120)$

\begin{tabular}{lc}
\hline \multicolumn{1}{c}{ Diagnosis } & Number of participants (\%) \\
\hline Total psychiatric disorders & $53(44.2)$ \\
Major depressive disorder & $7(5.8)$ \\
Dysthymia & $1(0.8)$ \\
Bipolar disorder & $22(18.3)$ \\
Panic disorder & $1(0.8)$ \\
Agoraphobia & $6(5.0)$ \\
Social phobia & $3(2.5)$ \\
Obsessive-compulsive disorder & $2(1.7)$ \\
Posttraumatic stress disorder & $2(1.7)$ \\
Alcohol use disorder & $23(19.2)$ \\
Schizophrenia & $7(5.8)$ \\
Generalised anxiety disorder & $2(1.7)$ \\
Antisocial personality disorder & $14(11.7)$ \\
ADHD & $11(9.2)$ \\
Suicidality & $36(30.0)$ \\
\hline
\end{tabular}

Dual diagnoses were allowed. ADHD: attention-deficit/hyperactivity disorder 
ly older $(\mathrm{p}=0.002)$. Gender, living situation, and annual family income were not associated with repeated crimes.

\section{Psychiatric disorders and repeated crimes}

Table 3 reports the relationships between psychiatric disorders and repeated crime. Alcohol use disorder was significantly associated with repeated crime $(\mathrm{p}=0.022)$. Major depressive disorder, dysthymia, panic disorder, agoraphobia, obsessive-compulsive disorder, posttraumatic stress disorder, schizophrenia, generalised anxiety disorder, and ADHD were not associated with repeated crime. However, first-time offenders were more likely to be diagnosed with each psychi- atric disorder considered, except for bipolar disorder and antisocial personality disorder. Suicidal ideation was not associated with repeated crime, as first-time offenders reported more suicidal ideation.

\section{Predicting recidivism from alcohol use disorder}

Alcohol use disorder was significantly associated with recidivism before covariate adjustment [odds ratio (OR), 3.080; 95\% confidence interval (CI), 1.118-8.483]. However, the association was no longer significant after adjusting for age, gender, living with parents, annual family income, probation reason, and suicidality (OR, 5.524; 95\% CI, 0.597-51.140).

Table 2. Demographic characteristics in first-time and repeat offenders $(N=120)$

\begin{tabular}{|c|c|c|c|}
\hline & First-time offenders $(\mathrm{N}=57)$ & Repeat offenders $(\mathrm{N}=63)$ & $\mathrm{p}$ value \\
\hline Age: mean (SD) & $15.89(1.72)$ & $16.75(1.24)$ & 0.002 \\
\hline Gender & & & 0.335 \\
\hline Men & $44(77.2)$ & $53(84.1)$ & \\
\hline Women & $13(22.8)$ & $10(15.9)$ & \\
\hline Living situation & & & 0.312 \\
\hline Both parents & $27(47.4)$ & $26(41.3)$ & \\
\hline Single parent & $23(40.4)$ & $33(52.4)$ & \\
\hline No parent & $7(12.3)$ & $4(6.3)$ & \\
\hline Annual family income & & & 0.336 \\
\hline Less than 10 million won & $7(12.3)$ & $5(7.9)$ & \\
\hline 10-20 million won & $13(22.8)$ & $12(19.0)$ & \\
\hline 20-30 million won & $4(7.0)$ & $11(17.5)$ & \\
\hline More than 30 million won & $7(12.3)$ & $9(14.3)$ & \\
\hline
\end{tabular}

Unless otherwise noted, data are presented as number (\%). SD: standard deviation

Table 3. Relationships between psychiatric disorders and repeated crime $(\mathrm{N}=120)$

\begin{tabular}{lccc}
\hline & First-time offenders $(\mathrm{N}=57)$ & Repeat offenders $(\mathrm{N}=63)$ & $\mathrm{p}$ value \\
\hline Total psychiatric disorders & $24(42.1)$ & $29(46.0)$ & 0.665 \\
Major depressive disorder & $4(7.0)$ & $3(4.8)$ & 0.707 \\
Dysthymia & $1(1.8)$ & $0(0)$ & 0.475 \\
Bipolar disorder & $10(17.5)$ & $12(19.0)$ & 0.832 \\
Panic disorder & $1(1.8)$ & $0(0)$ & 0.475 \\
Agoraphobia & $4(7.0)$ & $2(3.2)$ & 0.422 \\
Social phobia & $2(3.5)$ & $1(1.6)$ & 0.604 \\
Obsessive-compulsive disorder & $2(3.5)$ & $0(0)$ & 0.224 \\
Posttraumatic stress disorder & $2(3.5)$ & $0(0)$ & 0.224 \\
Alcohol use disorder & $6(10.5)$ & $17(27.0)$ & 0.022 \\
Schizophrenia & $4(7.0)$ & $3(4.8)$ & 0.707 \\
Generalised anxiety disorder & $2(3.5)$ & $0(0)$ & 0.224 \\
Antisocial personality disorder & $7(12.3)$ & $7(11.1)$ & 0.842 \\
ADHD & $7(12.3)$ & $4(6.3)$ & 0.261 \\
Suicidality & $22(38.6)$ & $14(22.2)$ & 0.051 \\
\hline
\end{tabular}

Unless otherwise noted, data are presented as number (\%). ADHD: attention-deficit/hyperactivity disorder 


\section{DISCUSSION}

Many juvenile offenders had psychiatric disorders, including alcohol use disorder, bipolar disorder, antisocial personality disorder, ADHD, schizophrenia, and major depressive disorder, in our study. The prevalences of psychiatric disorders in studies conducted in western countries were the following: alcohol abuse/dependence (4.7-6.4\%), bipolar disorder (1.7-6.8\%), ADHD (0.9-8.7\%), and major depressive disorder (2.2-5.3\%). ${ }^{17-19}$ Park et al. ${ }^{20}$ reported that $16.2 \%$ of 6-12-year-old Korean participants $(n=1,645)$ were diagnosed with DSM-IV disorders, including ADHD (5.9\%), major depressive disorder $(0.1 \%)$, and mania/hypomania $(0.1 \%)$. The psychiatric disorder prevalences differed slightly in the studies due to differences in the investigation methods and participant ages. Nevertheless, normal adolescents have lower prevalences of alcohol use disorder, major depressive disorder, bipolar disorder, and ADHD compared to the participants in the current study. Hodgin ${ }^{21}$ reported that men with major psychiatric disorders were 2.5 times more likely to commit crimes and 4 times more likely to commit violent crimes and women with major psychiatric disorders were 5 times more likely to commit crimes and 27 times more likely to commit violent crimes compared to the general population. Over half of subjects with major psychiatric disorders commit a crime before 18. In addition, Rosenblatt et al. ${ }^{22}$ reported that juvenile offenders display increased functional impairment due to conduct and externalising behavioural problems compared to the general adolescent population. Thus, major psychiatric disorders are strong risk factors for criminal behaviour among adolescents. Although not all adolescents with major psychiatric disorders commit crimes, they are at higher risk for aggressive behaviour until early adulthood ${ }^{23}$ which contributes to the likelihood of committing a crime. Therefore, diagnosing and treating major psychiatric disorders in adolescents who are on probation or imprisoned is important.

Of the juvenile offenders in our study, 30\% expressed suicidal ideation. A study of Korean adolescents in 10 juvenile correctional facilities $(n=1,682)$ reported that $15.2 \%$ had suicidal ideation during the past year. ${ }^{24}$ For juvenile detainees in western countries, the prevalence of suicidal ideation was $14.2-19.2 \%{ }^{25-27}$ Thus, the prevalence of suicidal ideation in juvenile offenders in this study was higher than those in previous studies. However, the prevalence of suicidal ideation in Korean adolescents over the previous 12 months was $18.4 \%{ }^{24}$ which was much lower than the prevalence in this study. In previous studies, juvenile delinquents have a higher risk of suicidal ideation compared with adolescents in the general population. ${ }^{28,29}$ Wasserman and McReynolds ${ }^{30}$ reported that juvenile offenders have a higher risk of suicidal behaviours than the general adolescent population. Antisocial behaviour, which is increased in youth with justice system contact, and the stress of incarceration itself are risk factors of suicidal ideation. ${ }^{31}$ Therefore, assessing and managing suicidal ideation in juvenile offenders is necessary because of their increased suicidal risk.

The prevalence of alcohol use disorder was higher among repeat offenders than among first-time offenders. Substance use during childhood and adolescence predicts criminal behaviour. ${ }^{32}$ Risk-taking increases with alcohol use, and individuals are insensitive to past rewards and recent losses when intoxicated. ${ }^{33,34}$ Consequently, people with alcohol use disorders display more violent tendencies and their negative consequences than the general population. Although alcohol use is more strongly associated with violent crime than with nonviolent crime, an association of alcohol use and violent is not clear. However, Murdoch and Ross ${ }^{35}$ reported that alcohol use is more strongly associated with criminal behaviour than psychopathology is. Binge drinking is significantly associated with violent crime and strongly predicts law violations. ${ }^{36} \mathrm{How}-$ ever, alcohol use disorder was not significantly associated with recidivism after adjusting for demographic factors, probation reason, and suicidality. Thus, in addition to mental illness itself, various factors, such as offense history, family problems, ineffective use of leisure time, delinquent peers, conduct problems, and psychopathology, affect recidivism. ${ }^{10}$ Alcohol use disorder frequently recurs, responds poorly to treatment, and coexists with several psychiatric disorders. Together, these studies suggest that more detailed assessments and therapeutic interventions are necessary to prevent recidivism in prisoners with alcohol use disorder.

Except for alcohol use disorder, psychiatric disorders were not significantly associated with repeated crime in the present study. Similarly, a Belgian study of detained male adolescents $(n=232)$ reported that common psychiatric disorders did not predict recidivism, while substance use and comorbid disorders increased the risk of substance-related recidivism. ${ }^{37}$ However, because the prevalences of dysthymia, panic disorder, social phobia, obsessive-compulsive disorder, posttraumatic stress disorder, and generalised anxiety disorder were low in the present study, the power to identify relationships between these disorders and recidivism was restricted. Although the mental health problems of juvenile offenders existed before their probation and detention, their problems can be associated with a lack of a social sport system, negative social perspective, and guilty conscience. Furthermore, Satterfield and Schell ${ }^{38}$ reported that hyperactivity, conduct problems, and antisocial behaviour are risks for juvenile and adult criminal behaviour. Therefore, the active management of mental health problems in juvenile offenders is necessary 
because these problems are directly related to conduct problems, hyperactivity, and antisocial behaviour. Although the effects of mental illness on adolescent recidivism are insignificant, these illnesses may contribute to recidivism if they are not properly treated and persist until adulthood.

The present study had several limitations. First, self-report tools on participant demographics, probation, and diagnoses were used. Therefore, the information may have been distorted by the participants. In addition, some participants did not respond to some questions, which decreased the data reliability. Second, the MINI, which was used to diagnose psychiatric disorders, does not fully cover children and adolescent psychiatric diagnosis. Thus, its use in children and adolescents may be limited. In addition, the Conners' Rating Scales were not sufficient to confirm ADHD diagnoses. Effective evaluations require tools that diagnose childhood- or adolescentspecific disorders, including oppositional defiant disorder, conduct disorders, ADHD, separation anxiety disorder, encopresis, and enuresis, such as the Korean version of the Kiddie-Schedule for Affective Disorders and SchizophreniaPresent and Lifetime Version. Future research should use a structured and objective diagnostic instrument and interviews with both adolescent participants and their parents to diagnose and evaluate psychiatric disorders. Third, the current findings do not allow conclusions about causalities between mental illness and recidivism. Longitudinal studies are needed to identify causal relationships. Last, generalisations of the results of our study are difficult because we studied a small number of adolescents from a single probation centre. Future studies should examine adolescents at multiple juvenile justice facilities, including those for system intake, detention, and probation.

The results of the present study demonstrated that adolescents on probation or parole had high incidences of psychiatric disorders, including alcohol use disorder, bipolar disorder, antisocial personality disorder, ADHD, schizophrenia, and major depressive disorder. Alcohol use disorder was significantly associated with repeated crime, while other psychiatric disorders were not. These results suggest that educational and treatment programs for psychiatric disorders, including alcohol use disorder, for juvenile offenders on probation or parole may help to prevent repeated criminal behaviour. Further research is needed at multiple juvenile justice facilities to accurately and comprehensively understand the effects of the juvenile offense conditions.

\section{Acknowledgments}

This study was supported by a research fund from Seoul National Hospital, Ministry of Health \& Welfare, Republic of Korea.

\section{REFERENCES}

1. Korean Institute of Justice. The White Paper on Crime. Yongin: Woorisa; 2014.

2. Korean Ministry of Gender Equality and Family. The White Paper on Adolescence. Seoul: Korea League of the Disable Voters; 2013.

3. Teplin LA, Abram KM, McClelland GM, Dulcan MK, Mericle AA. Psychiatric disorders in youth in juvenile detention. Arch Gen Psychiatry 2002;59:1133-1143.

4. Gosden NP, Kramp P, Gabrielsen G, Sestoft D. Prevalence of mental disorders among 15-17-year-old male adolescent remand prisoners in Denmark. Acta Psychiatr Scand 2003;107:102-110.

5. Rösler M, Retz W, Retz-Junginger P, Hengesch G, Schneider M, Supprian T, et al. Prevalence of attention deficit-/hyperactivity disorder (ADHD) and comorbid disorders in young male prison inmates. Eur Arch Psychiatry Clin Neurosci 2004;254:365-371.

6. Fazel S, Doll H, Långström N. Mental disorders among adolescents in juvenile detention and correctional facilities: a systematic review and metaregression analysis of 25 surveys. J Am Acad Child Adolesc Psychiatry 2008;47:1010-1019.

7. Fazel M, Långström N, Grann M, Fazel S. Psychopathology in adolescent and young adult criminal offenders (15-21 years) in Sweden. Soc Psychiatry Psychiatr Epidemiol 2008;43:319-324.

8. Wasserman GA, McReynolds LS, Ko SJ, Katz LM, Carpenter JR. Gender differences in psychiatric disorders at juvenile probation intake. Am J Public Health Res 2005;95:131-137.

9. Park SE. A study on relation between violent crimes juveniles and mental disorder disposition. Korean Police Stud Rev 2009;8:3-42.

10. Cottle CC, Lee RJ, Heilbrun K. The prediction of criminal recidivism in juveniles a meta-analysis. Crim Justice Behav 2001;28:367-394.

11. McReynolds LS, Schwalbe CS, Wasserman GA. The contribution of psychiatric disorder to juvenile recidivism. Crim Justice Behav 2010; 37:204-216.

12. Stoolmiller M, Blechman EA. Substance use is a robust predictor of adolescent recidivism. Crim Justice Behav 2005;32:302-328.

13. Hoeve M, McReynolds LS, Wasserman GA, McMillan C. The influence of mental health disorders on severity of reoffending in juveniles. Crim Justice Behav 2013;40:289-301.

14. Sheehan DV, Lecrubier Y, Sheehan KH, Amorim P, Janavs J, et al. The Mini-International Neuropsychiatric Interview (MINI): the development and validation of a structured diagnostic psychiatric interview for DSM-IV and ICD-10. J Clin Psychiatry 1998;59(Suppl 20):22-33.

15. Yoo S, Kim Y, Noh J, Oh K, Kim C, Namkoong K, et al.Validity of Korean version of the mini-international neuropsychiatric interview. Anxiety Mood 2006;2:50-55.

16. Bahn G, Shin M, Cho S, Hong K. A preliminary study for the development of the assessment scale for ADHD in adolescents: reliability and validity for CASS (S). J Korean Acad Child Adolesc Psychiatry 2001;12: 218-224.

17. Wittchen HU, Nelson CB, Lachner G. Prevalence of mental disorders and psychosocial impairments in adolescents and young adults. Psychol Med 1998;28:109-126.

18. Costello EJ, Mustillo S, Erkanli A, Keeler G, Angold A. Prevalence and development of psychiatric disorders in childhood and adolescence. Arch Gen Psychiatry 2003;60:837-844.

19. Merikangas KR, He JP, Burstein M, Swanson SA, Avenevoli S, Cui L, et al. Lifetime prevalence of mental disorders in US adolescents: results from the National Comorbidity Survey Replication-Adolescent Supplement (NCS-A). J Am Acad Child Adolesc Psychiatry 2010;49:980989.

20. Park S, Kim BN, Cho SC, Kim JW, Shin MS, Yoo HJ. Prevalence, Correlates, and Comorbidities of DSM-IV Psychiatric Disorders in Children in Seoul, Korea. Asia Pac J Public Health 2015;27:1942-1951.

21. Hodgins S. Mental disorder, intellectual deficiency, and crime: evidence from a birth cohort. Arch Gen Psychiatry 1992;49:476-483. 
22. Rosenblatt JA, Rosenblatt A, Biggs EE. Criminal behavior and emotional disorder: comparing youth served by the mental health and juvenile justice systems. J Behav Health Serv Res 2000;27:227-237.

23. Johnson JG, Cohen P, Smailes E, Kasen S, Oldham JM, Skodol AE, et al. Adolescent personality disorders associated with violence and criminal behavior during adolescence and early adulthood. Am J Psychiatry 2014;157:1406-1412.

24. Kim S, Kim H, Seo DC, Lee DH, Cho HI. Suicidal ideation and its correlates among juvenile delinquents in South Korea. Osong Public Health Res Perspect 2014;5:258-265.

25. Rohde P, Seeley JR, Mace DE. Correlates of suicidal behavior in a juvenile detention population. Suicide Life Threat Behav 1997;27:164-175.

26. Kenny DT, Lennings CJ, Munn OA. Risk factors for self-harm and suicide in incarcerated young offenders: implications for policy and practice. J Forensic Psychol Pract 2008;8:358-382.

27. Kretschmar JM, Flannery DJ. Displacement and suicide risk for juvenile justice-involved youth with mental health issues. J Clin Child Adolesc Psychol 2011;40:797-806.

28. Thompson MP, Ho CH, Kingree JB. Prospective associations between delinquency and suicidal behaviors in a nationally representative sample. J Adolesc Health 2007;40:232-237.

29. Matsumoto T, Tsutsumi A, Izutsu T, Imamura F, Chiba Y, Takeshima T. Comparative study of the prevalence of suicidal behavior and sexual abuse history in delinquent and non-delinquent adolescents. Psychia- try Clin Neurosci 2009;63:238-240.

30. Wasserman GA, McReynolds LS. Suicide risk at juvenile justice intake. Suicide Life Threat Behav 2006;36:239-249.

31. Shaffer D, Pfeffer CR. Practice parameter for the assessment and treatment of children and adolescents with suicidal behavior. J Am Acad Child Adolesc Psychiatry 2001;40:24S-51S.

32. Van Kammen WB, Loeber R, Stouthamer-Loeber M. Substance use and its relationship to conduct problems and delinquency in young boys. J Youth Adolesc 1991;20:399-413.

33. McMillen DL, Smith SM, Wells-Parker E. The effects of alcohol, expectancy, and sensation seeking on driving risk taking. Addict Behav 1989;14:477-483.

34. Lane SD, Cherek DR, Pietras CJ, Tcheremissine OV. Alcohol effects on human risk taking. Psychopharmacology 2004;172:68-77.

35. Murdoch D, Pihl RO, Ross D. Alcohol and crimes of violence: present issues. Int J Addict 1990;25:1065-1081.

36. Richardson A, Budd T. Young adults, alcohol, crime and disorder. Crim Behav Ment Health 2003;13:5-16.

37. Colins O, Vermeiren R, Vahl P, Markus M, Broekaert E, Doreleijers T. Psychiatric disorder in detained male adolescents as risk factor for serious recidivism. Can J Psychiatry 2011;56:44-50.

38. Satterfield JH, Schell A. A prospective study of hyperactive boys with conduct problems and normal boys: adolescent and adult criminality. J Am Acad Child Adolesc Psychiatry 1997;36:1726-1735. 